February 15, 2007

Project Title: Molecular Markers of Lung Cancer in Workers from the MAYAK Nuclear Enterprise: Final Report

Project 2.6

Principal Investigators: Steven A. Belinsky, Ph.D., Lovelace Respiratory Research Institute, Albuquerque, NM USA

Vitaliy Telnov, M.D. Southern Ural Biophysics Institute

Ozyorsk, Russia 


\section{Overview of Project}

The molecular mechanisms that result in the elevated risk for lung cancer associated with exposure to radiation have not been well characterized. Workers from the MAYAK nuclear enterprise are an ideal cohort in which to study the molecular epidemiology of cancer associated with radiation exposure and to identify the genes targeted for inactivation that inturn affect individual risk for radiation-induced lung cancer. Epidemiology studies of the MAYAK cohort indicate a significantly higher frequency for adenocarcinoma and squamous cell carcinoma (SCC) in workers than in a control population and a strong correlation between these tumor types and plutonium exposure. Two hypotheses will be evaluated through the proposed studies. First, radiation exposure targets specific genes for inactivation by promoter methylation. This hypothesis is supported by our recent studies with the MAYAK population that demonstrated the targeting of the p16 gene for inactivation by promoter methylation in adenocarcinomas from workers (1). Second, genes inactivated in tumors can serve as biomarkers for lung cancer risk in a cancer-free population of workers exposed to plutonium. Support for this hypothesis is based on exciting preliminary results of our nested, case-control study of persons from the Colorado cohort. In that study, a panel of methylation markers for predicting lung cancer risk is being evaluated in sputum samples from incident lung cancer cases and controls.

The first hypothesis will be tested by determining the prevalence for promoter hypermethylation of a panel of genes shown to play a critical role in the development of either adenocarcinoma and/or SCC associated with tobacco. Our initial studies on adenocarcinoma in MAYAK workers will be extended to evaluate methylation of the PAX $5 \alpha$, PAX $5 \beta$, H-cadherin, GATA5, and bone morphogenesis 3B (BMP3B) genes in the original sample set described under Preliminary studies. In addition, studies will be initiated in SCC from workers and controls to identify genes targeted for inactivation by plutonium in this other common histologic form of lung cancer. We will examine methylation of the p16, $\mathrm{O}^{6}$-methylguanine-DNA methyltransferase (MGMT), and death associated protein kinase genes ([DAP-K], evaluated previously in adenocarcinomas) as well as the new genes being assessed in the adenocarcinomas.

The second hypothesis will be tested in a cross-sectional study of cancer-free workers exposed to plutonium and an unexposed population. A cohort of 700 cancer-free workers and 700 unexposed persons is being assembled, exposures are being defined, and induced sputum collected at initial entry into the study and approximately 1-year later. Exposed and unexposed persons will be matched by 5-year age intervals and smoking status (current and former). The frequency for methylation of four genes that show the greatest difference in prevalence in tumors from workers and controls will be determined in exfoliated cells within sputum. These studies will extend those in primary tumors to determine whether difference in prevalence for individual or multiple genes are detected in sputum samples from high-risk subjects exposed to plutonium. Follow-up of this cohort offers the opportunity to validate these endpoints and future biomarkers as true markers for lung cancer risk.

The objectives of this proposal will be achieved through three specific aims.

1. Determine the frequency for methylation of the PAX5 $\alpha$, PAX5 $\beta$, H-cadherin, GATA5, and BMP3B genes in adenocarcinomas from plutonium-exposed workers and unexposed subjects.

2. Determine the frequency for methylation of the p16, MGMT, DAP-K and genes listed under aim 1 in squamous cell carcinomas from plutonium-exposed workers and unexposed subjects. 
3. Establish a prospective cohort of cancer-free persons exposed to plutonium and an unexposed population. Determine at entrance into the cohort the cross-sectional frequency for methylation in exfoliated cells in sputum of the 4 genes most commonly methylated in tumors associated with plutonium exposure.

\section{Progress: 3/30/06 - 10/10/06}

The manuscript describing methylation of the GATA5, PAX5 $\beta$, and H-cadherin genes was submitted for publication and is under review. The abstract of the manuscript follows below.

Epigenetic inactivation of genes by promoter hypermethylation, a major mechanism in the initiation and progression of tobacco-induced cancer, has also been associated with lung cancer induced through environmental and occupational exposures. Our previous study of gene methylation in workers from the MAYAK nuclear enterprise identified a significantly higher prevalence for methylation of the p16 gene in adenocarcinomas from workers compared to tumors from non-worker controls. The purpose of this investigation was to determine whether genes in addition to p16 are "targeted" for silencing and whether overall gene methylation was more common in radiation-induced adenocarcinoma. Adenocarcinomas collected retrospectively from 66 workers and 63 non-worker controls were examined for methylation of the GATA-5, PAX5 $\beta$, and $\mathrm{H}$-cadherin genes. A significant increase in prevalence was seen for methylation of GATA-5 in tumors from workers compared to tumors from controls. The prevalence for methylation of PAX5 $\beta$ and H-cadherin did not differ in tumors from workers and controls. Evaluating the frequency for methylation of a five-gene panel revealed that $93 \%$ of adenocarcinomas from workers compared to $66 \%$ of tumors from controls were methylated for at least one gene. Moreover, a two-fold increase was seen in the number of tumors from workers compared to controls methylated for three or more genes. Increased frequency for inactivation of genes by promoter hypermethylation and the targeting of tumor suppressor genes such as GATA-5 may be major factors in the increased risk for lung cancer associated with radiation exposure.

Work was continued on Specific Aim 3. We have now conducted data analysis on methylation results obtained on sputum collected from 397 former workers. Methylation assays were conducted on the p16, MGMT, DAPK, RASSF1A, PAX5 $\alpha$, PAX5 $\beta$, GATA4, and GATA5 genes. These findings and the tables below were also provided in response to SRG comments on our last semi-annual report.

Three important findings have emerged from these studies. First, there is an increased odds for having methylation of 4 or more genes in sputum if exposure to external radiation exceeded the median level ( $>95 \mathrm{cG}$ ). In contrast, exposure levels for Qlung were not associated with increased odds for methylation of $\geq 4$ genes methylated in sputum, while there was a indication that high exposure to alpha radiation may associate with methylation of $\geq 5$ genes. Second we also calculated odds ratios for methylation where gamma radiation and Qlung (alpha radiation to the lung) were both in the model and results indicate these exposures act independently. Third, we compared multiplicity for methylation seen in sputum from the former MAYAK workers to our Lovelace cohort since we do not have controls from Ozyorsk yet (anticipate receipt in October). These results revealed a significant increase in the number of workers with methylation of 4 or more genes in their sputum compared to controls. 
Table 1. Demographic Summary of MAYAK cases

\begin{tabular}{|r|r|r|r|r|}
\hline gender & Frequency & Percent & $\begin{array}{r}\text { Cumulative } \\
\text { Frequency }\end{array}$ & $\begin{array}{r}\text { Cumulative } \\
\text { Percent }\end{array}$ \\
\hline female & 148 & 37.37 & 148 & 37.37 \\
\hline male & 248 & 62.63 & 396 & 100.00 \\
\hline
\end{tabular}

\begin{tabular}{|r|r|r|r|r|}
\hline agegroup & Frequency & Percent & $\begin{array}{r}\text { Cumulative } \\
\text { Frequency }\end{array}$ & $\begin{array}{r}\text { Cumulative } \\
\text { Percent }\end{array}$ \\
\hline$[\mathbf{4 0 , 6 5 )}$ & 85 & 21.46 & 85 & 21.46 \\
\hline$[\mathbf{6 5 , 7 0 )}$ & 89 & 22.47 & 174 & 43.94 \\
\hline $\mathbf{7 7 0 , 7 5 )}$ & 127 & 32.07 & 301 & 76.01 \\
\hline$>=75$ & 95 & 23.99 & 396 & 100.00 \\
\hline
\end{tabular}

\begin{tabular}{|r|r|r|r|r|}
\hline pack years & Frequency & Percent & $\begin{array}{r}\text { Cumulative } \\
\text { Frequency }\end{array}$ & $\begin{array}{r}\text { Cumulative } \\
\text { Percent }\end{array}$ \\
\hline nonsmoker & 208 & 52.79 & 208 & 52.79 \\
\hline $\mathbf{( 0 , 2 0 )}$ & 82 & 20.81 & 290 & 73.60 \\
\hline $\mathbf{2 0 , 4 0 )}$ & 61 & 15.48 & 351 & 89.09 \\
\hline$>=40$ & 43 & 10.91 & 394 & 100.00 \\
\hline
\end{tabular}


Table 2. Methylation Summary of MAYAK cases

\begin{tabular}{|r|r|r|r|r|}
\hline \multicolumn{6}{|c|}{ Number methylated out of 8 genes } \\
\hline count8 & Frequency & Percent & $\begin{array}{r}\text { Cumulative } \\
\text { Frequency }\end{array}$ & $\begin{array}{r}\text { Cumulative } \\
\text { Percent }\end{array}$ \\
\hline $\mathbf{0}$ & 56 & 14.14 & 56 & 14.14 \\
\hline $\mathbf{1}$ & 86 & 21.72 & 142 & 35.86 \\
\hline $\mathbf{2}$ & 97 & 24.49 & 239 & 60.35 \\
\hline $\mathbf{3}$ & 69 & 17.42 & 308 & 77.78 \\
\hline $\mathbf{4}$ & 49 & 12.37 & 357 & 90.15 \\
\hline $\mathbf{5}$ & 26 & 6.57 & 383 & 96.72 \\
\hline $\mathbf{6}$ & 12 & 3.03 & 395 & 99.75 \\
\hline $\mathbf{7}$ & 1 & 0.25 & 396 & 100.00 \\
\hline $\mathbf{8}$ & 0 & 0.00 & 396 & 100.00 \\
\hline
\end{tabular}

\section{Methylation for Individual Genes}

\begin{tabular}{|l|r|r|}
\hline Gene & \multicolumn{2}{|r|}{$\begin{array}{r}\text { Methylation frequency } \\
\text { (out of } \mathrm{N}=396 \text { ) }\end{array}$} \\
\cline { 2 - 3 } & $\mathrm{N}$ & $\%$ \\
\hline P16 & 92 & 23.23 \\
\hline MGMT & 140 & 35.35 \\
\hline RASF1A & 4 & 1.01 \\
\hline Dapk & 116 & 29.29 \\
\hline PAX5 $\alpha$ & 100 & 25.25 \\
\hline PAX5 $\beta$ & 86 & 21.72 \\
\hline GATA4 & 243 & 61.36 \\
\hline GATA5 & 111 & 28.03 \\
\hline
\end{tabular}


Table 3. Modeling Results

Odds Ratios ${ }^{*}$ and $95 \%$ confidence intervals for increased number of methylated genes by radiation category (above median vs below): Only one radiation variable in a model

\begin{tabular}{|l|r|l|l|l|}
\hline $\begin{array}{l}\text { Comparison } \\
\text { groups based } \\
\text { on number of } \\
\text { methylated } \\
\text { genes }\end{array}$ & Gamma & Qlung & Qbody & Dlung \\
\hline$\geq 3$ vs $<3$ & $1.1(0.7,1.7)$ & $1.0(0.7,1.5)$ & $1.0(0.7,1.6)$ & $1.0(0.6,1.5)$ \\
\hline$\geq 4$ vs $<4$ & $2.0(1.1,3.6)^{\#}$ & $1.0(0.6,1.7)$ & $0.9(0.6,1.5)$ & $0.9(0.5,1.5)$ \\
\hline$\geq 5$ vs $<5$ & $2.8(1.1,7.2)^{\#}$ & $1.6(0.8,3.2)$ & $1.2(0.6,2.4)$ & $1.0(0.5,2.0)$ \\
\hline
\end{tabular}

Cut-off values were approximately equal to the median exposure value:

Gamma: $\geq 100$ vs $<100$

Qlung: $\geq 2.2$ vs $<2.2$

Qbody: $\geq 40$ vs $<40$

Dlung: $\geq 0.20$ vs $<0.20$

* Adjusted for age, gender and smoking history

\# Significant at $p<0.05$

Table 4. Odds Ratios ${ }^{*}$ and $95 \%$ confidence intervals for increased number of methylated genes by radiation category (above median vs below): Both Gamma and Qlung in the model

\begin{tabular}{|l|r|r|}
\hline $\begin{array}{l}\text { Comparison } \\
\text { groups based } \\
\text { on number of } \\
\text { methylated } \\
\text { genes }\end{array}$ & Gamma & Qlung \\
\hline$\geq 3$ vs $<3$ & $1.1(0.6,1.7)$ & $1.0(0.7,1.6)$ \\
\hline$\geq 4$ vs $<4$ & $1.8(1.0,3.4)^{\#}$ & $1.1(0.6,1.8)$ \\
\hline$\geq 5$ vs $<5$ & $2.7(1.1,7.0)^{\#}$ & $1.7(0.8,3.5)$ \\
\hline
\end{tabular}

Cut-off values were approximately equal to the median exposure value:

Gamma: $\geq 100$ vs < 100

Qlung: $\geq 2.2$ vs $<2.2$

Qbody: $\geq 40$ vs $<40$

Dlung: $\geq 0.20$ vs $<0.20$

* Adjusted for age, gender and smoking history

\# Significant at $p<0.05$ 
Conclusion: Models (not shown) indicate that interactions between gamma and Qlung (alpha) radiation are not significant. The results from Tables 4 and 5 indicate that gamma and Qlung act independently. Although the Qlung results are not significant, there is a trend toward an association between high dose exposure to alpha radiation and methylation of 5 or more genes in sputum. Moreover, the joint effect of gamma and alpha radiation confer a 4.6-fold increased odds for methylation of 5 or more genes in persons with exposures above the median for both radiations.

Table 5. Comparison of MAYAK cases with Lovelace cohort

\begin{tabular}{|c|c|c|c|c|c|c|c|c|c|}
\hline \multirow{2}{*}{ Cohort } & \multicolumn{8}{|c|}{ Number of methylated genes (Number expected under $\mathrm{H}_{0}$ ) } & \multirow[b]{2}{*}{ Total } \\
\hline & 0 & 1 & 2 & 3 & 4 & 5 & 6 & 7 & \\
\hline MA & $\begin{array}{l}56 \\
(87.5)\end{array}$ & $\begin{array}{l}86 \\
(100.6)\end{array}$ & $\begin{array}{l}97 \\
(89.6)\end{array}$ & $\begin{array}{l}69 \\
(58.9)\end{array}$ & \begin{tabular}{|l|}
49 \\
$(33.9)$
\end{tabular} & $\begin{array}{l}26 \\
(17.2)\end{array}$ & $\begin{array}{l}12 \\
(7.8)\end{array}$ & $\begin{array}{l}1 \\
(0.5)\end{array}$ & 396 \\
\hline Lovelace & $\begin{array}{l}112 \\
(80.5)\end{array}$ & $\begin{array}{l}107 \\
(92.4)\end{array}$ & $\begin{array}{l}75 \\
(82.4)\end{array}$ & $\begin{array}{l}44 \\
(54.1)\end{array}$ & \begin{tabular}{|l}
16 \\
$(31.1)$
\end{tabular} & $\begin{array}{l}7 \\
(15.8)\end{array}$ & $\begin{array}{l}3 \\
(7.2)\end{array}$ & $\begin{array}{l}0 \\
(0.5)\end{array}$ & 364 \\
\hline
\end{tabular}

p-value from Chi square test $<0.0001$, indicating a significant difference in the methylation distributions between the two groups. A comparison of the observed frequency and the expected frequency shows that in the MAYAK cohort there are fewer people than expected in the no methylation group and more people than expected in the $\geq 2$ methylated genes categories, with statistically significant differences reached at 4 methylated genes. Similarly for the LSR cohort, there are more people than expected in the no methylation group and fewer people than expected in the $\geq 2$ methylated gene categories, with statistically significant differences reached at 4 methylated genes. These differences are also illustrated below in Figure 1.

Figure 1. Comparison of Methylation Index by Cohort

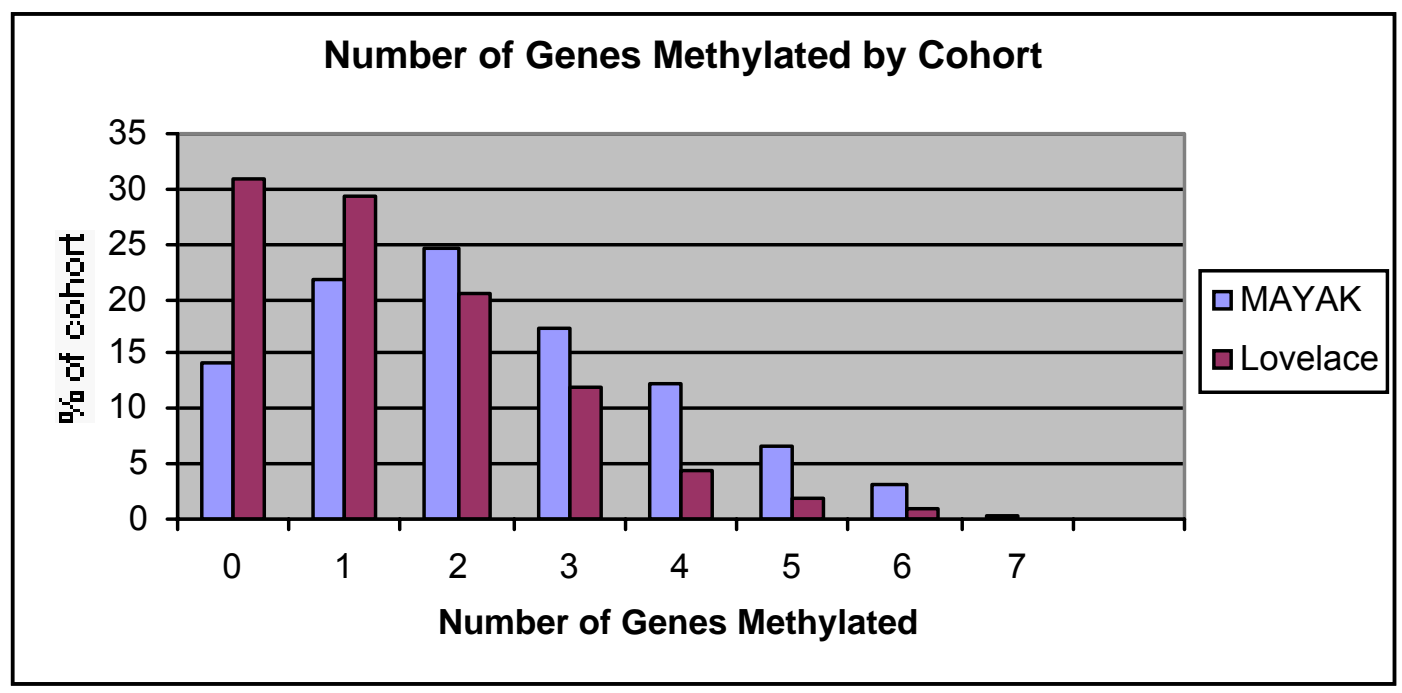


Our goals for the next 6 months of this project are to receive DNA that has been isolated from sputum collected from enrolled controls (persons who did not work at MAYAK), and obtain demographic and exposure history from these persons. In addition, we anticipate receiving vital statistics for the original MAYAK workers on which methylation assays have been performed. If we receive additional funding, methylation assays will be performed on the DNA obtained from the 400 controls, data analysis conducted, and a manuscript submitted. If additional funds are not forthcoming, the project will have to be discontinued. It is my opinion that the population-based studies being conducted in the MAYAK cohort and controls will add tremendous value to understanding the additional risk for lung cancer associated with radiation exposure. Such data will be used to help develop methylation as an intermediate biomarker for identifying early lung cancer. Key to such studies is the unique opportunity to follow this unique cohort that the Russian team has assembled (now approaching 1,000 persons) through assaying longitudinally the sputum samples collected to assess how methylation index (number of genes methylated in the sputum sample) changes. Ultimately, through follow-up incident lung cancer cases will emerge and associations to methylation index assessed. Such studies would constitute a new project with longitudinal follow-up and analysis of methylation in longitudinal samples.

\section{Work Performed by the Russian Team}

During March-October the following tasks were implemented:

1. Enroll 300 - 350 controls and obtain sputum sample. Conduct cytological analyses of sputum cells and extract DNA from sputum and lymphocytes.

2. Obtain follow-up sputum from 80-100 plutonium-exposed workers, cytological analyses of sputum cells, and extract DNA from sputum and lymphocytes.

3. Search and receive demographic, dosimetry, medical, smoking status and vital status for 400 plutonium-exposed workers and controls.

4. Establish a computer database for control persons and longitudinal sputum samples.

5. Paperwork arrangement and processing for transfer of biomaterial to the American collaborators in March.

\section{Goals for the next 6 months}

Funding for the Russian team has been stopped. 